\title{
Rendering controversial socioscientific issues legible through digital mapping tools
}

\author{
Anne Solli ${ }^{1}$ (D) Åsa Mäkitalo ${ }^{1} \cdot$ Thomas Hillman $^{1}$ \\ Received: 19 February 2018 / Accepted: 26 October 2018 / Published online: 28 November 2018 \\ (C) The Author(s) 2018
}

\begin{abstract}
Giving students opportunities to work collaboratively with complex online information is important for the development of democratic citizenship, but providing and structuring these opportunities poses pedagogical challenges. In this study, we investigate how digital mapping tools developed within Science and Technology Studies (STS) are used by upper secondary science students for the collaborative exploration and ordering of controversial socio-scientific issues (SSIs) found online. Our sociocultural approach to detailed analysis of video data reveals how students synchronously construct shared interactive visualizations and respond collaboratively to mediating features of the network visualization tool for handling multiple perspectives and information encountered online. The analysis shows how the tool-mediated activity provided means for students to work out what is relevant and useful in a corpus of online data. We unpack the details of the complex dynamics of this process of evaluating and categorizing websites, uncovering ways that interaction with emerging knowledge artefacts is co-constitutive of participation in the local setting. In particular, this analysis reveals how the tool-mediating activity slows down the process of judging and categorizing online material in terms of criteria such as institutional status, trustworthiness, and position of a controversy. Furthermore, it reveals that alignments and misalignments between the digital tool used and students' own logics prompted students to engage in productive collaborative negotiation of how to make sense of a controversy.
\end{abstract}

Keywords SSI · Digital mapping tools · Mediational means · Complexity · Information seeking · Science education

\section{Introduction}

In this study, we explore how upper secondary science students use a network visualization tool for the collaborative exploration and ordering of websites encountered when searching

Anne Solli

anne.solli@gu.se

1 Institution for Learning, Communication and Education, University of Gothenburg, Box 100, S-405 30 Gothenburg, Sweden 
and browsing for controversial socio-scientific issues (SSIs). This activity responds to ways that contemporary citizens in industrialized countries are faced with handling a complex knowledge-intensive world where current developments in science and technology are a prominent part of the socio-political landscape. A contemporary concern is that internet is promoting an increasingly fragmented and polarized citizenry, and it has been argued that restrictions and limitations of digital tools may impact citizenship in the twenty-first century (Choi et al. 2017; Flaxman et al. 2016) Through networked digital media, an overwhelming amount of conflicting knowledge claims from different actors and fields have become readily available for many and raise issues of concern. Consider for instance the issues of vaccinations, climate change and genetically modified organisms. Understanding these issues of concern calls for the creation of activities in classrooms that enable young people to reflect critically and carefully by examining the actors, their claims, interests and affiliations (Walsh and Tsurusaki 2017; Zeidler 2014). Key to such examinations are the abilities to navigate and critique the content available via information and communication technologies with the supporting strategies necessary for handling the abundance of information (Chung and Neuman 2007). Perhaps the most widely used tool for navigating online information is search engines, but they have been criticized for introducing bias, most notably via selection and ranking algorithms that tend to favor popular, sponsored and institutionally accredited sources (Granka 2010; Introna and Nissenbaum 2000). Given these concerns and the curricula in many jurisdictions that require schools to address issues of scientific and information literacy, schools are faced with the challenge of helping students to develop the digital competence to constructively handle controversial SSIs encountered online.

Despite the relevancy of the issues, there is still little empirical evidence for what teachers and students actually do with material about SSIs found by students on the internet (Klosterman et al. 2012). Some research has explored collaborative information seeking in educational contexts (Lin and Tsai 2012; Wu and Tsai 2011), however few studies have been based on direct observation (Knight and Mercer 2014). While several reports have explicitly highlighted students' perceptions of SSI complexity as a desired educational outcome (Pedretti and Nazir 2011), studies of the search behaviors of upper secondary science majors that have been conducted generally indicate the need for more guidance for students when they search for SSIs online (Hsu et al. 2014). The provision of such guidance necessitates approaches for helping students to both explore and order information, and to conceptualize and unpack controversies.

One means to represent the complexities of the information encountered online in a condensed and more readable form has been termed controversy mapping (Venturini 2010b). Venturini and Latour (2010) argue that a relevant approach to mapping controversies is the extraction and analysis of digital information through the digital traces a controversy leaves. Engaging with a controversy through digital inquiry is a potential means to help clarify SSIs for secondary school students and their peers by providing means to make visualizations that can both encompass the complexity and make the complexity legible. Our study reports on the introduction of digital mapping tools to a school context. In our empirical case, students are not provided information on controversial SSIs by teachers. Instead, controversy mapping is used as an attempt to equip students with the means to observe and describe on-going issues for themselves, but embedded within a classroom project designed by teachers. It is well documented that the introduction of new technologies in existing practices is complex and time-consuming and that there is a need to more closely examine how the meaning and functions of CSCL applications such as digital mappings tools are actually constituted in 
practice (Arnseth and Ludvigsen 2006; Stahl et al. 2006). Similarly, while issues relating to the implementation of 'effective' learning technologies are of importance to the field of education, it has been argued that greater attention needs to be paid to how digital technologies, often not developed for educational settings, are actually being used in schools (Selwyn 2011). Responding to these calls, the aim of this study is to contribute to our understanding of how technology originally used for teaching and research at universities to investigate sociotechnical debates (Venturini 2010b) enables productive collaboration and discussion in the classroom. This is accomplished by examining how students engage with digital mapping tools to make the complexity of SSIs encountered online more legible. Before presenting the specific network visualization tools used by the students to explore and order the complexities of the issues encountered online, we will review CSCL research that has reported on students handling of information encountered on the internet and students use of visualization tools for unpacking complex issues.

\section{A socio-cultural approach to students' use of digital mapping tools}

In this article, we adopt a sociocultural approach to the study of students ordering of complexities using digital mapping tools. In a sociocultural tradition the analogy of 'tools' was introduced to argue that cultural artifacts are fundamental for human activities and are recognized as the means through which we as humans make meaning and accomplish significant cultural change (Wertsch 1998). The notion of artifacts in this tradition, resists the distinction between the material and the ideational as a premise, and instead set out to investigate, for instance, how particular tangible designs such as pen and paper mediate social activities in particular ways with particular consequences when relied upon in use. Artifacts most importantly provide ways to pursue specific activities, act on things, and coordinate collaboration in situated practices. We study action by taking into account the interdependencies between students and artefacts such as mapping tools, and focus on social interaction with artefacts. With this approach, the unit of analysis becomes tool-mediated activities (Säljö 1999). That is, the ways participants engage in activities with, and in relation, to the technologies and other artefacts present in a situation. This analytical stance provides a way of accounting for how human action is socioculturally embedded, contingent on social, institutional, and material conditions (Wertsch 1998).

The visualization tools used in this study have been developed for controversy mapping by researchers in university contexts. When we study how these tools are put to use in a school context, we need to take into account that students pay attention to, describe and act in response to what the school context allows and encourages (Säljö 2010). When students engage with these tools, it becomes relevant to analyze how they orient towards the task they have been given, and what they need to collaboratively accomplish in the specific setting. Ethnographic data make it possible to scrutinize how the activities of students are part of locally situated contexts and institutional practices. Our approach to CSCL, takes into account the interactional and contextual features of human discourse and action, and students' ideas and perspectives on topics are understood to be generated and sustained through the social and material features of interaction displayed through students collaboration with tools. From this theoretical perspective, collective construction of a more legible representation of a controversy in a map, is made possible by the mutual coordinated interactions by the different participants. 


\section{Research on collaborative information seeking online}

As mentioned in the introduction, studies of students' handling of information found online based on direct observation are relatively scarce and there have been calls for greater attention to be paid to this research area. This gap in the literature is of particular relevance for the CSCL field where a recent position paper suggesting future directions for the field argues that the necessity of handling a multiplicity of perspectives and uncertainties of information in the internet age is of particular concern (Wise and Schwarz 2017). The authors suggest that in relation to these issues, an emerging goal for CSCL is to help people effectively engage in the process. They argue that the field must expand the scope of its investigations having focused on tools of their own design to also include social media (Wise and Schwarz 2017).

While there is little research to date based on direct observations studies of students collaborative handling of information online, studies that address how to support students engaged in seeking information online are of relevance to the present study - particularly those dealing with science related complex issues (Hsu et al. 2014; Lin and Tsai 2012; Stadtler and Bromme 2007; Wu and Tsai 2011). For students working on such issues it is challenging to select and examine high-quality relevant sources. For example, Wu and Tsai (2011) tested learning outcomes of guided online searching on nuclear power usage. Students instructed to search for information related to different perspectives such as technology; ecology and economy were reported to outperform an unguided group in terms of reasoning capabilities and conceptual understanding. Similar results were reported by Stadtler and Bromme (2007) who studied students searching for information on a medical topic. Students who received metacognitive prompts where students were asked to reflect on how well they understood the information and to indicate the sources of that information, outperformed control groups in terms of knowledge about sources, and produced more arguments relating to the sources of information. Also structuring the search process, the use of a social bookmarking application to support productive behavior was investigated by Lin and Tsai (2012). The application enabled asynchronous internet exploration, and students who exhibited an active engagement including searching, making bookmarks and commenting on the bookmarks of others were reported to exhibit a "deep" level of cognitive engagement and tended to become aware of valuable online resources for the assignment (Lin and Tsai 2012). However, irrespective of the kind of support students receive, the normative framing of the school context will play a role as reported in a recent study conducted by Forte (2015). One finding was that although the design of the activity in the study aimed at supporting open collaboration to build a textual artifact, specific established school norms still became relevant as students framed tasks in institutionally sanctioned ways (Forte 2015).

Acknowledging the relevance of providing students with supporting strategies when engaging with online information (Lin and Tsai 2012; Stadtler and Bromme 2007; Wu and Tsai 2011) and recognizing the institutional framing when analyzing what students attend to (Forte 2015), the current study aims to investigate how the students work collaboratively to represent online information about controversial issues in a condensed and readable form with a visualization tool that has not been developed for pedagogical use in schools.

\section{Research on visualization creation and use for complex issues}

Learning with representations is a recurring issue in educational research (Furberg et al. 2013) and constructing representations of domain understanding has been shown to improve student 
knowledge (Kolloffel et al. 2011). Kolloffel et al. (2011) compared the effect of different representational tools in inquiry learning and concluded that concept maps in particular can direct students' attention to specific aspects of a subject matter and argued that such artefacts express students understanding of a domain, crystallizing it and opening up the domain to be discussed, elaborated, manipulated and reorganized. In this way, concept maps have been reported to be productive for individual student's abilities to reason, make decisions and structure knowledge about climate change (Eggert et al. 2017). Schwendimann and Linn (2016) conducted a study building on a tradition of using expert-generated artifacts as a reference for self-evaluation of student work (Hmelo-Silver et al. 2007). The students worked in an inquiry-based online environment and produced so called Knowledge Integration Maps, concept maps which embedded non-normative ideas on evolution. Expert-generated concept maps were used as exemplars to help identify gaps in students understanding.

The present study aims to add to this body of research on two levels. First, we analyze how students synchronously co-construct visualizations, although not as "externalizations of students ideas" as is the case with concept mapping (Kolloffel et al. 2011). Rather the network visualization tools provide some means for students to work out what is relevant and useful, when exploring a controversial issue from a corpus of online data consisting of traces of their own searching and websites visited. Students in our study are tasked with producing maps in order to open up the controversy to be explored, however unlike Schwendimann and Linn (2016), these maps are not like expert-generated concept maps. Instead, the student-produced maps in this study, are dynamic performances of the 'magmatic' landscapes of controversial issues as they unfold online (Venturini 2010a, 2010b) where the goal is to make accountable depictions of this landscape. Second, by observing the students actions in situ (Knight and Mercer 2014) we aim to analyze the details of the complex dynamics of a process that involves categorization and evaluation of websites, acknowledging interaction with emerging knowledge artefacts as co-constitutive of participation in the local setting.

\section{Network visualization tools for controversy mapping}

In this study, the students use new methods developed for the analysis of the increasingly complex and interconnected nature of controversies. The methods include software such as $G e p h i^{1}$ that makes it possible to explore, manipulate and visualize networks of online data. Networks of such data are understood as sets of nodes connected by edges. These tools make use of algorithms and traditional statistical techniques to help locate various useful points in the data, which are then visualized as maps through graph theory (Jacomy et al. 2014). The map is the data network corpus transformed into a visual form. These maps are both instruments of navigation of the landscape (here: the controversy) and tools to present it. In the activity studied here, the students use is a two-step protocol. First, students use a tool ${ }^{2}$ to collect data while they search for information regarding a particular SSI. The tool gathers information about how websites are connected through hyperlinks in the form of both inbound and outbound links and it builds a corpus of these data. Students then export their corpus of hyperlinks as a network file that can be used by Gephi to make a graph where the nodes represent the websites and the edges represent the hyperlinks between them. Gephi displays the connections between sites and the relative centrality of a website in relation to a particular issue (Fig. 1).

\footnotetext{
${ }^{1}$ Gephi: an interactive visualization and exploration tool for all kinds of networks

${ }^{2}$ Navicrawler: is used with Firefox. Downloaded at: http://tools.medialab.sciences-po.fr/
} 
When the online data is to be re-presented in visual form using Gephi, and a digital map of 'actors' is generated, the students choose the design. The strategy adopted in Gephi is to allow users to see the consequences of their choices in real time. The 'live' spatialization process makes it possible for the students to observe that there is no such thing as a unique placement in the network. They can act on the network by changing the ranking of the nodes, or filtering nodes and edges. The software passes on modifications and updates the visualization in real time, re-computing and continuously updating the placement of nodes. For example, one way to visualize the status of websites in the network is to emphasize those nodes that have many inbound hyperlinks. This can be achieved by scaling nodes based on the number of inbound hyperlinks so that websites that are linked to by many others, appear larger in the network. In addition, the program can be instructed to arrange the nodes spatially based on features such as the quantity of edges between them. Thus, websites that connect to each other through many individual hyperlinks appear closer together, while those that do not, appear farther apart. Once spatialized, users can colorize nodes to create category additional schemes. The students in this study could thus mobilize three main visual attributes when creating controversy maps: size, position and color. The task of making a representation of the controversy through these visual attributes in interaction with the program is indeed entangled with exploring the controversy itself: "Left alone, observations in social cartography quickly become too complex to be managed. That is why the task of unfolding the complexity of controversies should never be separated from the task of ordering such complexity. Exploration and representation always come together in cartography."(Venturini 2010a, p797).

\section{Controversy mapping as project work in the science classroom: The empirical setting}

The project was conducted in an upper-secondary school in a suburban area outside a major city in Sweden where participating students were admitted into a somewhat competitive upper secondary science program and had thus engaged in more science education than the average Swedish citizen. Data was collected in a year 12 class of 18-year-old upper secondary school science students working with controversy mapping as part of a three-week long science-insociety project in November 2015. The students' project was collaboratively developed by teachers from the upper secondary school, researchers in education and science studies, along with a pedagogical developer focused on integration of information technologies (IT). The school team involved four experienced teachers (Chemistry, Physics, Swedish and Biology). The students worked in small groups on a targeted controversy - electronic waste, HPV vaccine, prenatal diagnosis or animal testing in research. At the start of the project, the students were provided with goals they were expected to achieve and the requirements for the different grades.

The students were to access, explore, analyze and evaluate different kinds of content in a variety of forms encountered on the Internet in accordance with the goals specified in the national curriculum. ${ }^{3}$ They were provided with information about the project including the

\footnotetext{
${ }^{3}$ The Swedish curriculum for science in upper secondary school includes aims for students to develop an ability to assess different types of information sources, being able to distinguish between scientific and non-scientific claims https://www.skolverket.se/undervisning/gymnasieskolan/laroplan-program-och-amnen-igymnasieskolan/gymnasieprogrammen)
} 


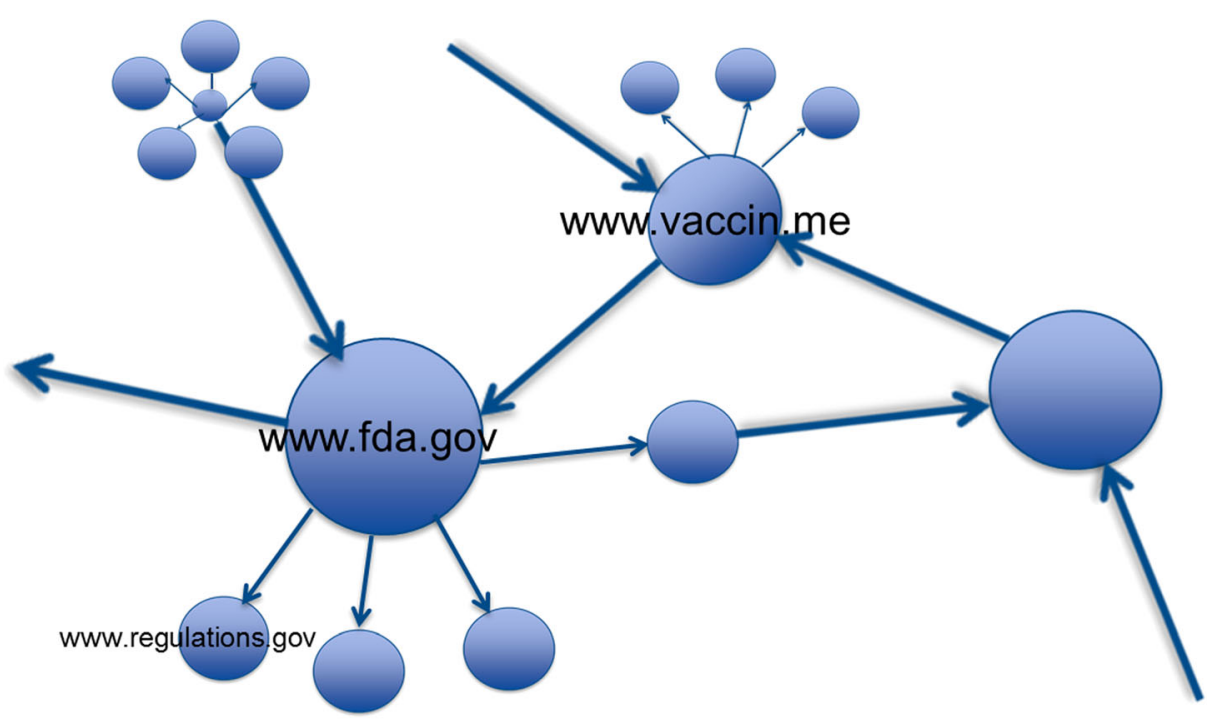

Fig. 1 An illustrative re-construction showing how websites connected to the issue of HPV vaccine are connected when visualized through Gephi. The students in this study used the search term 'HPV vaccine' to produce maps typically based on visits to approximately 400 websites

various tasks to prepare for the activities, and grading criteria relevant for the subjects of Swedish and Science. The purpose of the project was to work with the following objectives from the science curriculum:

Students should be given the opportunity to develop an ability to evaluate different types of sources and to distinguish between scientific and non-scientific claims.

Students should be given the opportunity to develop interest in scientific issues. The education should provide an understanding of how science and development of society mutually have influenced and influence each other and, in particular, highlighting the role of science in sustainable development issues.

Students will also be given the opportunity for ethical discussions about the role of science in society.

The overall project was introduced to students by their teachers while the notion of controversies and the digital mapping tools were introduced by the first author. Following this introduction, students started working according to the following procedure:

1. Surfing and scraping the Internet on one controversial issue. The web browser extension Navicrawler logs the URLs for all the webpages visited

2. Selecting relevant data produced with Navicrawler and importing them to Gephi

3. Re-presenting the data in visual form using Gephi, generating a digital map of 'actors' involved in the controversy (the activity in focus for this paper). For this activity, students worked on individual computers side by side, updating their maps in collaboration. They were instructed that the map was to be used in later activities as an aid in explaining and discussing their controversy. Students were instructed in the following way:

"The purpose of your research is to get a broad picture of the controversy in question. When you have your map, you are supposed to analyze it with regard to the following 
questions: What 'sides' are present in the controversy? Who are the stakeholders? What is their respective position in relation to each other? What connections are there between them? What arguments do you find on the different 'sides'? What are these arguments based on? What interests do the stakeholders have?" (from the written instructions provided by teachers)

4. Sharing and discussing the map with peers having worked with other controversies (Fig. 2)

5. Participating in a debate, enacting an actor identified in the controversy

To prepare for this task, students were provided with information and questions:

"You are now to enact a role (the role will be assigned to you) of one of the actors you have identified in the mapping - you will then prepare for the press conference... you should be prepared for answering questions such as:

How would you describe the area? What is your attitude towards it? What arguments do you have for your case? What kind of opposing argument do you usually encounter? Which interests do you represent? What kind of perspectives? What are your arguments based on? Why?

6. Taking part in a reflective seminar

\section{Data production and analytical procedure}

The project activities of two student groups were documented using tripod mounted video cameras positioned to record all the students in each group with microphones placed on the Tables (40 $\mathrm{h}$ per group were collected in the research project). In addition, recordings of

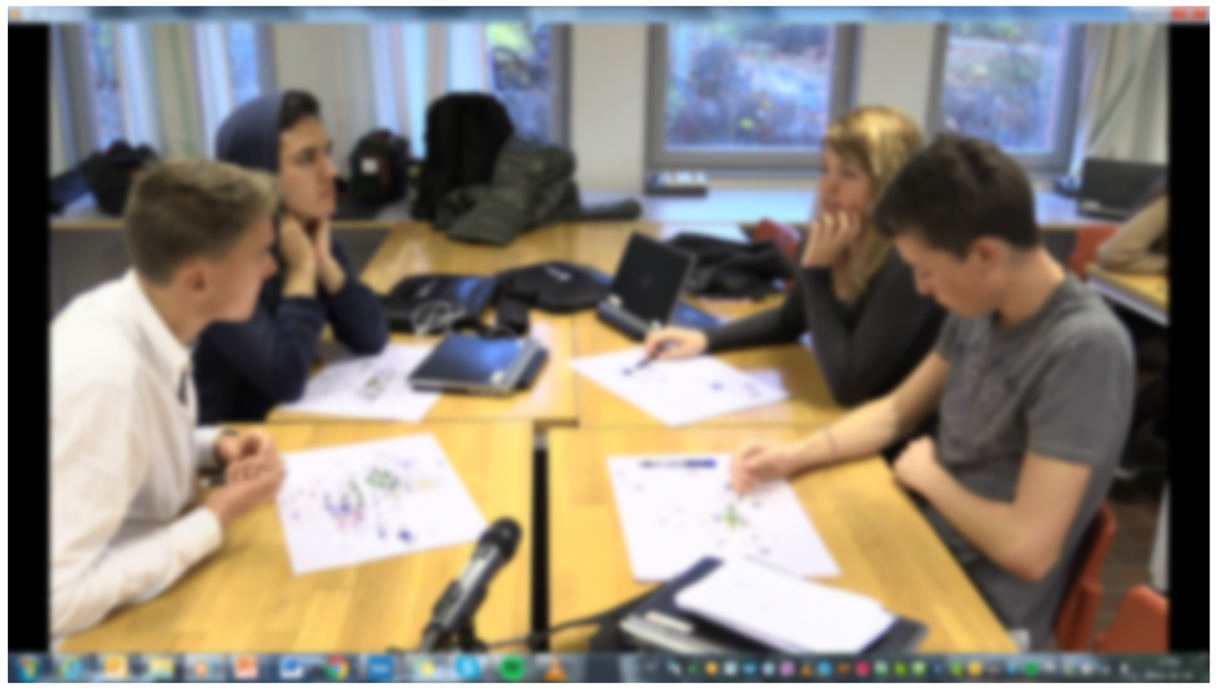

Fig. 2 Group discussions, presenting and discussing maps produced with peers 
students' laptop screens (one for each group) through screen-capture software were collected (6 h per group). This screen-capture software was controlled by the student with the software on their computer. Use of both video cameras and screen-capture software on students' laptops offered a detailed record of relatively complex group work arrangements that included the use of specific software, web resources and printed materials. The recordings were then synchronized enabling us to analyze interactional features. Given our interest in student use of the network visualization tool for exploring and analyzing a controversy, we selected a session of Step 3 of the students' process, "Re-present the data in visual form using Gephi" as the analytical focus in this study. We analyzed the process in which the students worked to make the map legible through categorization of the websites, and coloring of the corresponding nodes accordingly (90 min of synced video recordings) (Fig. 3).

In order to provide a sense of continuity and to follow the developments of one controversy map, we decided to use excerpts from one group. We selected the group working with the HPV vaccine controversy, since the map was significantly more elaborated than the map on prenatal diagnosis. Since we were interested in how the students made the complexity of the map legible, a simpler map implies less collaborative activity and thus less interaction of interest among students and with the tools.

The applied analytical procedure was video-based interaction analysis (IA) used to investigate student activity in complex, technology-mediated learning environments (Cekaite 2009; Furberg 2016; Jordan and Henderson 1995; Krange and Arnseth 2012). This implies that each utterance in a selected excerpt is considered in relation to the on-going interaction. As a result, the focus is not on the meaning of single utterances, but on how meaning is created within the exchange of utterances (Linell 1998). This analytical approach ensures that the participants' concerns and their activities are scrutinized. We explore how the students orient to and formulate points they find relevant in relation to visual means provided by the map, i.e. how the map mediates students' activity. Following the tradition of IA the analytical procedure was conducted iteratively by viewing the video recordings and the transcripts to distinguish patterns in the participants' activities through their interaction with each other and with the digital technology. Through the episodes, we examine in detail how students are using and responding to the various mediating features of the tool to understand what the tools provide in terms of support, restriction, and guidance for action. The recorded activities ( $90 \mathrm{~min}$ of synced

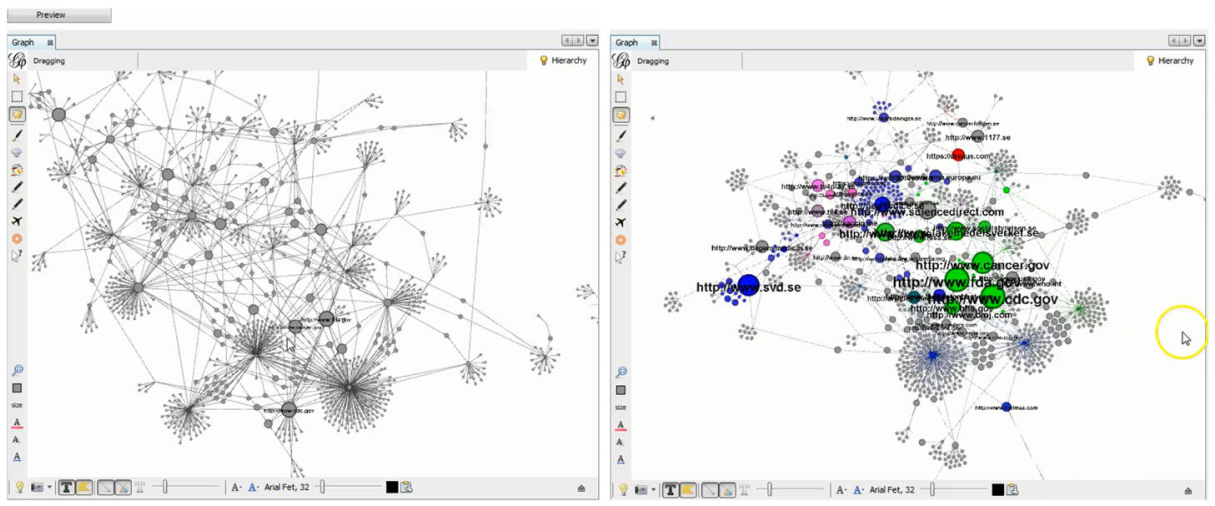

Fig. 3 The left map from the beginning of the session, and to the right a map towards the end of the session. Colors represent different categories of actors: Green $=$ public, Blue $=$ media, Pink = against the vaccine 
video recordings) were watched and discussed; observations of students' interactions were made by the first author and brought to joint video seminars for analytical discussions with the rest of the research group. The recordings were transcribed at a general level with detailed transcriptions performed once episodes of particular relevance had been identified and translations to English made for publication (see Appendix 1 for transcription conventions). We use episodes as a bounded sequence, key events focused on the treatment of some problem or issue (Linell 1998). Some episodes often reoccurred during the session; such as 'exploring connections', 'getting an overview' or 'struggling to understand knowledge claims', whereas the first episode 'initial exploration' of the data body occurred in the beginning. The four episodes were selected as time progresses sequentially to illustrate the variability and context-specific use of the tools through the students' process of ordering complexity during the session. Instances in every episode are provided through excerpts.

The following research question has guided our analysis: How do digital mapping tools developed for exploring and visualizing controversial issues in the STS field, together with the local context, mediate student's selection, analysis, and critical review of online material?

\section{Findings}

In the following, we present an account of how students described the controversy in terms of three emergent category schemes: actors as institutions such as media and government agencies, as being positioned as opposing the vaccine, and as truthful or not. As described earlier, this activity follows sessions where students collected the URLs of all the webpages they visited and imported them into a network visualization program. By means of the selected excerpts we will follow Ana and Ted, each having constructed a map on their computer in parallel from the same data. In this way, they work together, but in parallel, updating their maps from each other's findings. They make distinctions between types of actors, and color the nodes representing them accordingly. After about an hour, a third member of the group, Vicky joins. She participates by recalling the names of actors and adjudicating between claims made on their websites. For analysis, this activity has been divided into four sequential episodes of student interaction that proceed as follows:

1. Initial exploration. The students initially work according to certain principles afforded by the tools, and are offered starting points to examine network nodes made prominent by the algorithms in the visualization tool.

2. Getting an overview. The students turn from identifying and coloring nodes based on their visual prominence to talking about how they are to use the map in accordance with the task they have been given to explain the controversy. Here, the category 'actor with a position in the controversy' becomes relevant.

3. Exploring connections. The students attend to the edges between nodes to hypothesize about how they should be categorized based on their neighbors. In this episode, the students decide to reexamine the website vaccine.me which had previously been categorized as 'media'.

4. Struggling to understand actors' claims. Ana and Ted focus their attention on the website vaccine.me in order to establish a category by reading and interpreting claims on the website to see whether they could understand them as taking a stance against the vaccine. 
Vicky interacts as well, also engaged in interpreting the claims, but is instead focused on evaluating their trustworthiness.

In the first three episodes, we can follow how the students orient to and formulate arguments they find relevant in relation to the visual means provided by the map. During the activity, the students focus on nodes made visually prominent (episode 1), use the map to get an overview of the various actors displayed (episode 2), and explore connections between those actors (episodes 1 and 3). In the fourth episode, the students struggle to understand the claims made by different actors. Through analysis of these episodes, we will show how the production and representation of a controversy map is a complex interplay between students, tools and the school setting.

\section{Episode 1: Initial exploration of the data body}

In order to start the task of exploring and categorizing the map, the students begin by removing a number of nodes with no connections on the outskirts of the map. They then go on to examine the visually larger nodes on the map to determine the type of category to designate for the actors. In the following excerpt, Ana and Ted are engaged in examining the largest nodes and use the colorization feature of the software to visualize the categories "public /informative" (green) and "newspapers/media" (blue).

\section{Excerpt 1}

100. Ana: this one, this one is in the middle ( (finds $S B U^{4}$ and zooms in)), thiswas (.) the public and media (.) It is SBU yes (.) but it was something like, swedish something (looking over at Ted's screen), with medications and stuff

101. Ted: but it was like public

102. Ana: yes

103. Ted: it is green

104. Ana: ( (colors the node SBU green))

105. Ted: TV4 ${ }^{5}$

106. Ana: ( (moves the pointer between three relatively big nodes, (Fig. 4)))

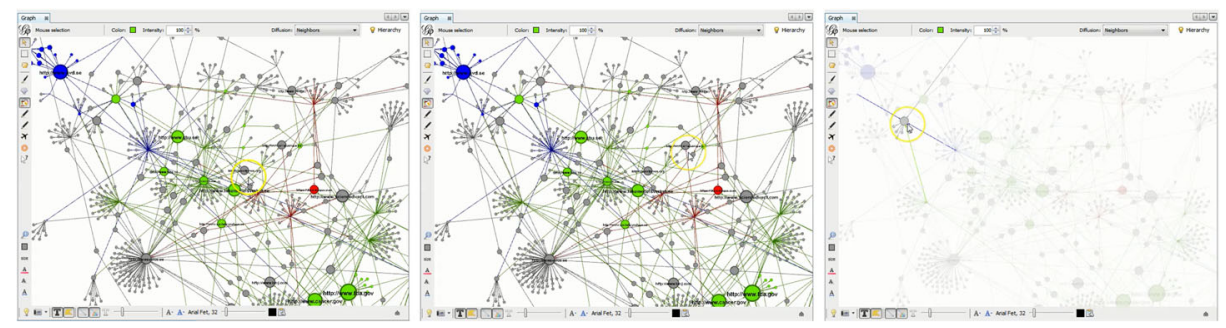

Fig. 4 the cursor (highlighted with a ring by the screencast software) is moved between relatively big, uncolored nodes on the map

\footnotetext{
${ }^{4}$ Swedish agency for health technology assessment and assessment of social services

${ }^{5}$ A national television channel
} 


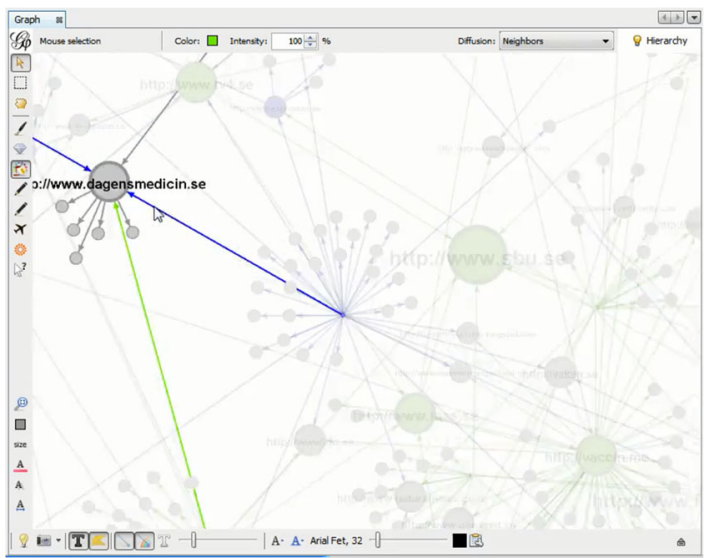

Fig. 5 Ana is zooming in on medicine today [dagensmedicin.se], the cursor highlights the node and its links

107. Ana: medicine today ((zooming in on the node (Fig. 5))) is it public, no, it feels a bit more

108. Ted: ((turning towards Ana's screen)) wordpress.org that is (.) media

109. Ana: yes

110. Ted: the medical journal also gets blue

111. Ana: ( (uses the coloring feature in the program and "loads" the cursor with the blue color) ), wordpress.org ( (Ana clicks on wordpress.org to color it blue, she focus the pointer on wordpress.org and it becomes evident that even a another node was colored, vaccin (Fig. 6)) )

112. Ana: vaccine point me okay yes, and which one was red? forum ( (zooms out, finds the red node and zooms back in) )

113. Ana: I think, forums may link to other forums ((follows red arrows (the tip is inside the circle of the cursor) and points to Newsvoice, a relatively big node with two red arrows pointing to it (Fig. 7)))

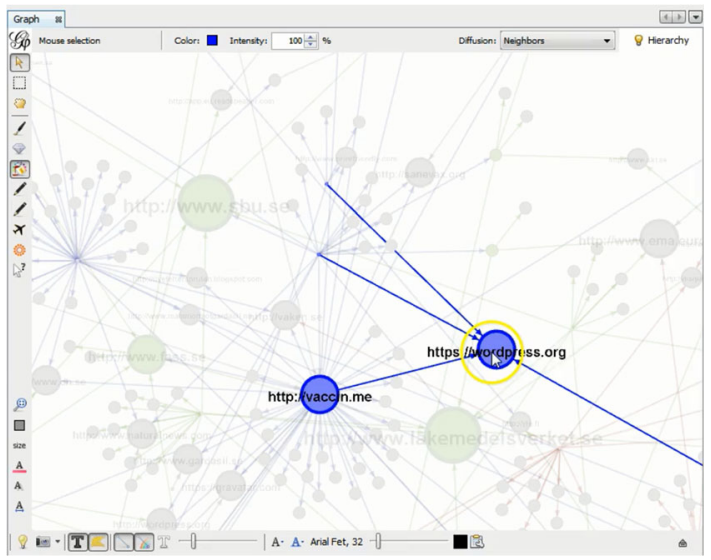

Fig. 6 The cursor highlights the node wordpress.org and its neighbor vaccine.me 
114. Ana: newsvoice what was that?

115. Ted: I don't know can check up on that

116. Ana: I don't know, think it was quite good (1s) newsvoice it

feels like some newspaper

117. Ted: where did you find that? ((look at his own screen))

118. Ana: newsvoice, what was it dot com or was it ( looks at the map to see what is says)) point point se aha. Public service for real it says here.

In this first episode, we see how the students initially work according to certain principles made available by the algorithms. The map as mediational means offers starting points to examine the nodes made prominent by the algorithms in the visualization tool. The excerpt shows how the students are orient to visually large, centrally located nodes. Initially, they attend to "this one is in the middle", which they collaboratively categorize as "public" (100-104). Then, Ana moves her pointer between relatively large nodes, not yet assigned a category (106) and moves on to find candidates for the category "media" (108 - 110). Ana colors the large Wordpress.org node blue according to a suggestion from Ted (111). The software's colorization feature then automatically colors a node that points to Wordpress.org, vaccin.me. This automated feature is not intentionally chosen by the students and it is possible to have the nodes colored individually as well. Another feature of the software then enables Ana to visually highlight a selected node (Wordpress.org), and the connections to other nodes (vaccin.me), as well as the labels for these nodes, while the other elements of the graph are dimmed (111). She then recognizes the auto-coloring by saying "vaccine okay" (112) but does not comment further. Instead, she moves on to specify the category "Forum" that was denoted only once, proposing that "forums may link to other forums" and following the link from Forum to the node Newsvoice. At this point, the students recognize that this actor needs to be examined on the web to be categorized (114-118). The students then move continuously between examination of the nodes on the map and interpretation of the claims made by the corresponding actors on their websites. Certain

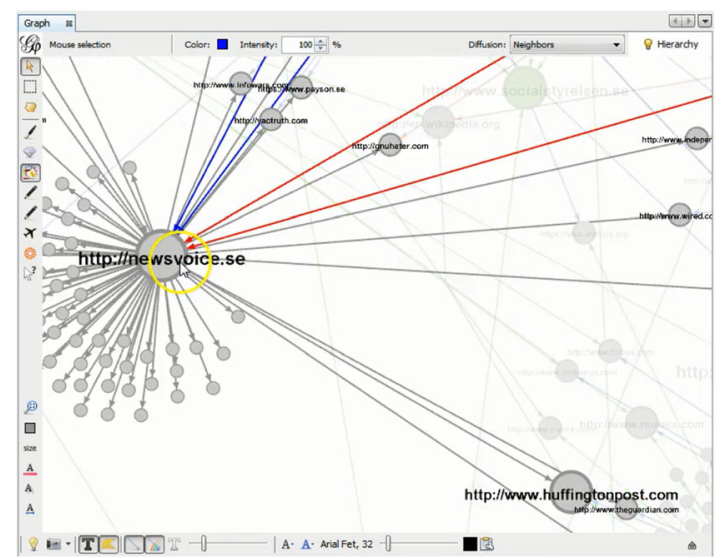

Fig. 7 The cursor highlighting the node newsvoice 
categorizations are quickly made based on the names of the websites such as $S B U$, two medical journals and Wordpress.org, but in many cases, the students' analysis involves more detailed examination. This is the case with Newsvoice which is initially assigned the category "media" ("public service for real it says here"), but then receives closer examination. Later in Episode 4, we will show how students attend to another site that receives further examination, vaccine.me.

In Episode 1, students orient to and formulate points they find relevant in relation to visual means provided by the map. Here the map mediates the students' activity as two features of the tool guide the students' perception and action when exploring the controversy. Whereas a Google search produces a list of websites ordered by Google's PageRank algorithm, the map the students work with is generated from a network that uses an algorithm which moves the nodes so that highly connected websites are placed close to each other and centrally on the map while websites with no or few links are placed peripherally. The centrally located nodes are thus assumed to be more central in the network, while peripherally located nodes with few links are assumed to be less relevant. The students make use of this feature when they initially delete nodes in an effort to reduce some of the complexity. The feature also occasioned the students to hypothesize about categories since highly linked nodes could possibly belong to the same category (113), "forums may link to other forums". Similarly, the feature of the software that generates the size of nodes proportional to their number of in-links, supports students in initially focusing on the visually largest nodes.

While the position and size of nodes on the map is determined by an algorithm acting on the available data, a third visual means, color, is used manually by the students' to categorize actors based on analysis of the claims made on the corresponding websites. The coloring feature itself is provided by the software and students use it to accomplish the task of making a legible map by visualizing different categories of actors. It also seems to function as a way to remember what they have categorized and what is left to explore (as we will highlight in Episode 2). However, the autocoloring feature is activated by default and causes additional nodes beyond those selected by the students to be colored as well. Ana makes productive use of this autocoloring feature to explore associations around the single actor in the category "Forum". When following red edges from this red node to find more nodes that could be designated with that category, she finds Newsvoice.

The students learn to manage the tool sufficiently to be able to move forward with the task, operating on and categorizing the content of the websites, whereas the tool itself, Gephi, only operates on the relationships between nodes. The students on the one hand, and the features of the Gephi software on the other, enact quite different takes on the websites in the network. Gephi does not take the content of the websites into account when constructing the map by representing websites as nodes, only considering the digital links between them, whereas it seems central to the students to operate on and categorize the 'actors' represented by the nodes. Gephi is a general visualization software for all kinds of networks and has many functions that are not relevant for the students. Consequently, the students re-purpose Gephi as a tool fit for their specific task. They try out features and decide if and how they can be useful. Gephi then, is both an exploration and visualization tool for the network the students are interacting with. In a sense, for the students who have no experience with Gephi as a multipurpose tool, Gephi plus the specific visualized network is the tool at hand. In this case, we can see how the multiple technical possibilities do, at least initially, seem to interfere with the students' work by potentially using a logic different to the students' categorizing practices. 
In the next episode, the students turn from identifying and coloring the nodes based on their visual size to talking about how to use the map to perform the task they have been given to explain the controversy. Here, categorizing actors as taking a position in the controversy becomes particularly relevant.

\section{Episode 2 Getting an overview}

Just prior to the interaction in the excerpt below, the students talked about what they needed to accomplish and finish for this task. They decide that they should finalize the visualization of a map, identify actors, interpret the map and explain its appearance. The episode begins as Ana is sweeping across the map with the cursor and notices how most of the largest nodes are colored blue and green. She pauses the coloring activity and initiates talk about how far they have come and what they have done so far:

\section{Excerpt 2}

200 Ana: ( (moves the pointer around the map)) it feels like (.) It feels like we have still (2s) [ colored]

201 Vicky: ( (leans forward, looks at Ana $)) \Rightarrow>$ [ we have] a pretty good idea about< $(2 \mathrm{~s})$ or uh what were you gonna say?

202 Ana: ( (not looking at Vicky, looking at her computer) ) : uh yes I was only thinking about the map here (.) But you were gonna say we have a pretty good idea

203 Vicky: I still think (.) I feel we have a pretty good idea of (1s) ( (looking straight ahead))

204 Ted: ( (leans forward towards Vicky))

205 Vicky: the thing itself ((her hand circular motion)) sort of in itself eeh

206 Ana: well I feel you have an idea, but I don't know if you should (.)

207 Vicky: ( (looking at Ana )), mm

208 Ana: well I feel a need to know how to explain (.) that is planning how to explain it sort of

209 Vicky: mm what the press conference will involve

210 Ana: really it is-((A teacher approaches the group and observes the discussion))

$211 \mathrm{Ted}$ : and then it's difficult to identify the big actors ( (Ana looks at Ted's screen) ) that are against sort of from the map, I think 212 Ana: from the map yes exactly that is what the problem is I feel

213 Ted: I would like to-

214 Ana: or how have you done it, let me have a look ( (looks at Ted's screen))

$215 \mathrm{Ted}$ : there, there is diet democracy, itwas against, and it is lying in the middle of everything, I would like to have 
216 Ana: ( (checking her own map)) how did you do it? Did you search data laboratory ( (she locates diet democracy on the map by searching in Gephi's data laboratory, a searchable list of all nodes on the map, asks the program to locate the node, the node diet democracy is centered on the screen, Fig. 8)), uh, diet (.) democracy

$217 \mathrm{Ted}$ : I would like to have out here ((pointing to the side of his screen)) 218 Teacher: ( (breaks to address the whole class about a possibility to travel to Stockholm for a competition) )

219 Ana: ( (locates the node and colors it pink (Fig 9)) )
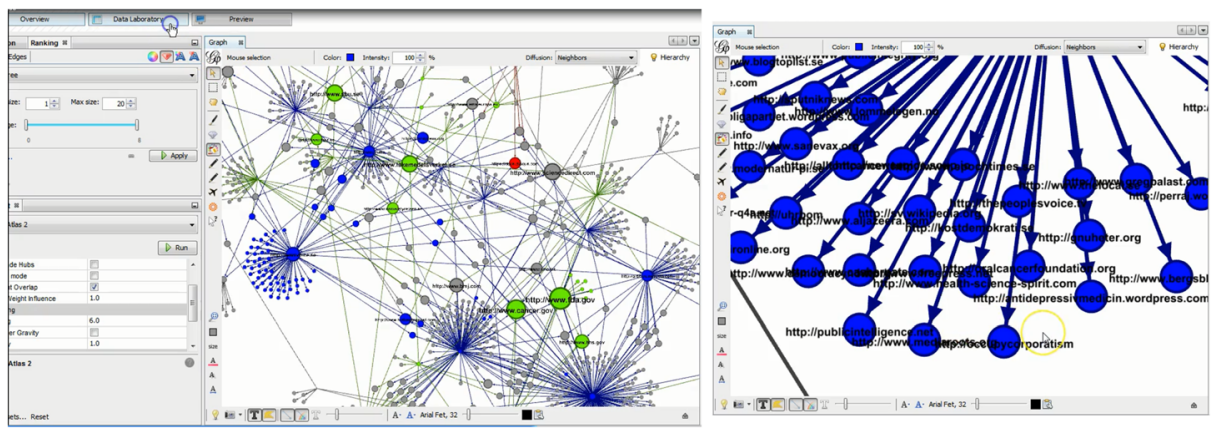

Fig. 8 (left) Opening data laboratory to find a small node on the map (right) the program places the node centrally on screen

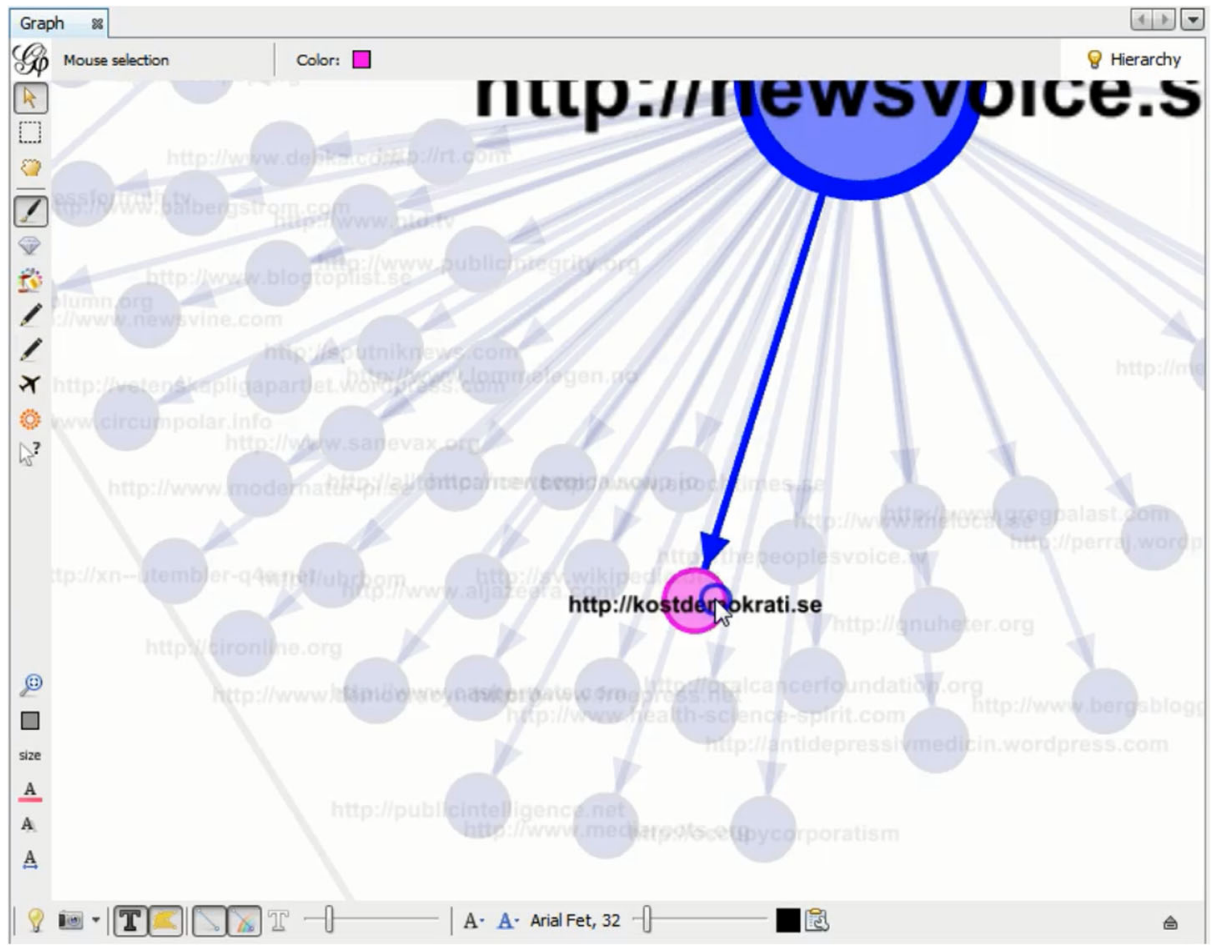

Fig. 9 Ana locates dietdemocracy [kostdemokrati] and colors it pink 
In this second episode, the map functions as a mediational means for the students to gain an overview of the various nodes categorized and to notice that no prominent actors with a position in the controversy have been identified. In this way, the map shifts in meaning and purpose; now becoming a means to address an audience with the controversy in mind. In the excerpt, the students initially take a step back and formulate what they understand; that they might begin to understand the controversy and that they need to be able to explain the controversy by using the map. First, Ana moves her cursor around the map noting that they have colored a great deal followed by a somewhat hesitant discussion about what they "have a pretty good idea about" and whether it is the controversy map or the "thing in itself" (200 - 205). They anticipate the need to be able to explain the controversy from the map in future activities like the press conference where different positions are to be enacted, and planned as the format for the summative assessment at the end of the project (208-211). When the map becomes mediational means for addressing an audience with the controversy in mind, the category "against" becomes relevant, and an example of this category, diet democracy, is identified (215). Here, the students address a concern and a difficulty with the map, how to find the "big ones" that are against the vaccine (211-212). The problem Ted describes with the nodes representing actors that are "against" is that they are placed centrally, among many other nodes of other categories $(213,215)$ while he would have preferred them to be clustered by themselves (217). As a solution to the problem of finding specific nodes, Ana discovers, with help from Ted (214), another feature of the software that allows them to locate the node 'diet democracy' by searching for it in a list view of the nodes and then asking the software to center the node on the screen (216).

The students address that the "big ones against" - are difficult to find on the map thereby showing awareness that there are big actors in the sense of being important in explaining the controversy and not merely big as in visually big dots. They make distinctions between the controversy per se and the visualization they work on; showing that they understand that the map does not directly mirror the controversy. Rather, it is made clear that the map is a result of exploring the controversy and can thus be used to explain it. Here we see an example of when Gephi is not immediately useful for the task that the students are faced with, as the map does not make certain nodes of the controversy easily visible, as understood form the student perspective. Instead, it becomes evident to the students that it is the structure and relations between websites that is visualized and that the software is accordingly "content blind". Hence the program does not necessarily make available the salient actors according to the students' logic (in terms of being important for the controversy, the amount of "followers", or in terms of "trustworthiness"). When the tool does not guide the students in how to proceed, they decide on a course of action together based on the task provided by the teachers and in anticipation of what they will need for the upcoming summative assessment activity. Having decided upon a course of action, in the third episode the students make particular use of the edges visualizing how nodes are linked together and make hypotheses about how neighboring actors may belong to the same category.

\section{Episode 3 Exploring connections}

In this episode, the students continue to work on finding nodes on the map that they can categorize as being "against" the vaccine and color them pink: 


\section{Excerpt 3}

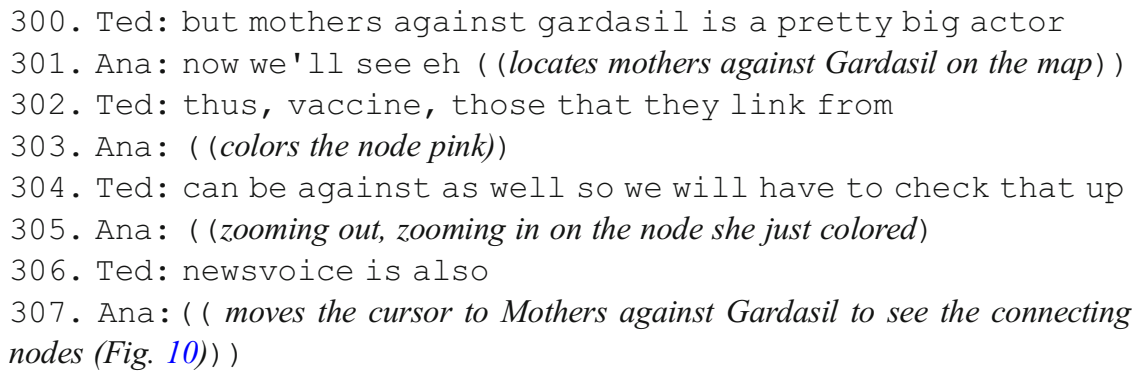

Ted and Ana use the map to find more candidates for the category "against" by investigating the nodes that are linked to from Mothers against Gardasil (300 - 307), as this is identified as a" "big", pretty big actor". Ted identifies two actors that they need to examine, Vaccin.me (302) and Newsvoice (306), and in response Ana quietly examines the map to see for herself what Mothers against Gardasil links to (307). The two identified nodes had previously been colored blue (media) by the software (Vaccine) and manually by the students (Newsvoice). By attending to the visual means provided, the relations visualized by

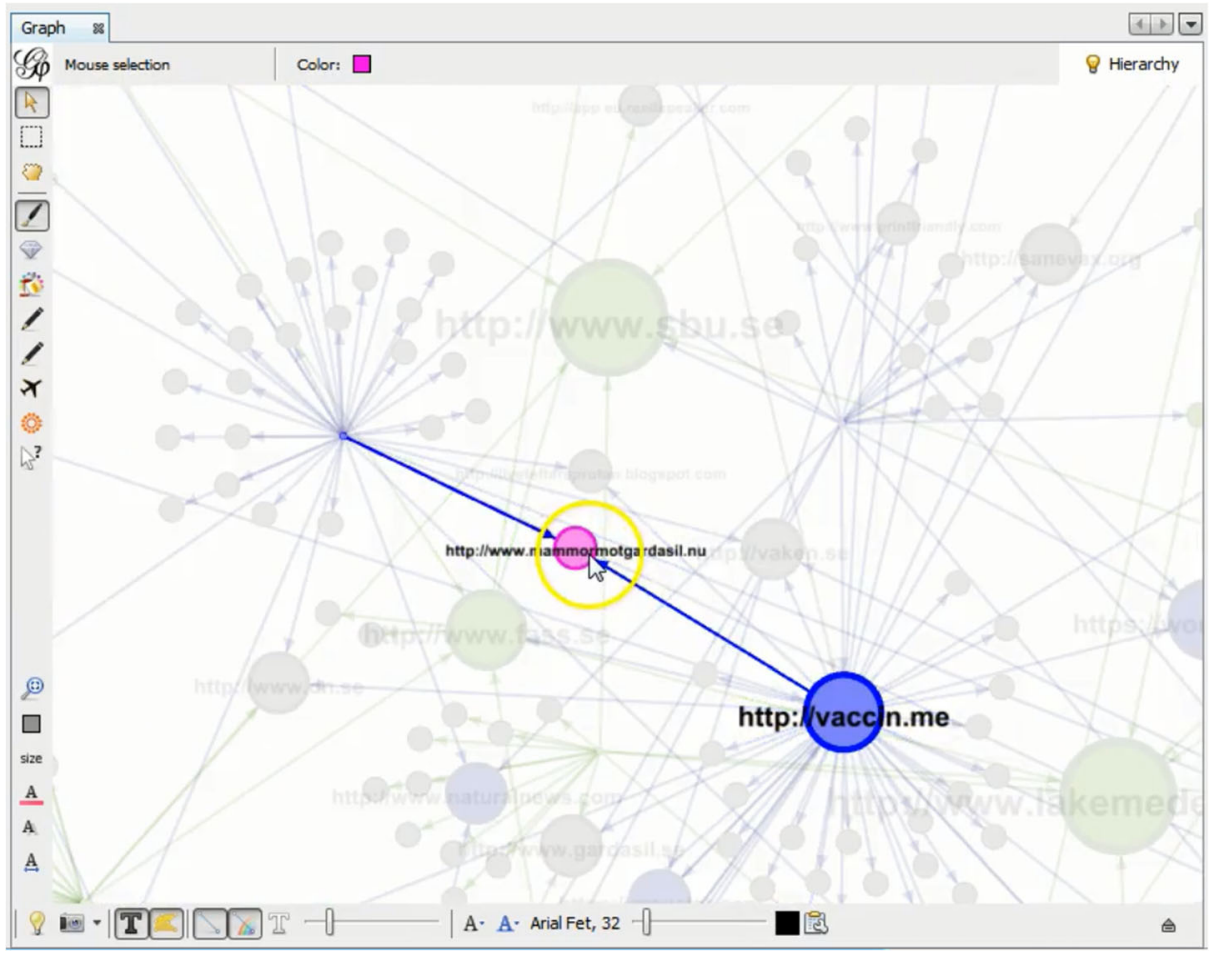

Fig. 10 Cursor highlighting Mothers against Gardasil [mammormotgardasil.nu] and its neighbor Vaccine [vaccine.me] 
the colored edges between nodes, students are able to discern clusters of nodes rather than working on one node at a time in isolation.

In episodes 2 and 3, we see how the students focus their attention on the categorization of a number of actors potentially opposed to the HPV vaccine: Diet democracy, Mothers against Gardasil, Vaccine and Newsvoice. They recognize two of them from earlier encounters on websites (Diet democracy, and Mothers against Gardasil), but the other two are made visible by being connected to the Mothers against Gardasil node. They make use of the feature that close nodes often have more in common than those that are far apart. Here, we see another example of the sharing of tasks among Ana, Ted and Gephi. Ted introduces the idea that they need to check up on some actors because of edges that have been rendered between them, while Ana takes a closer look at the relationships between nodes on the map. The tool is designed for individual use, so students work in parallel and engage in a dialogue mediated by the visual displays. They replicate each other's performances making sure that their maps are coordinated when the other is making a categorization and by sharing nodes between them to work efficiently. This arrangement means that they must make explicit what they do and make their categorization work known to each other, and hence engage in negotiation and discussion of categories.

Following the decision to investigate certain actors further mediated by the visual means of the map showing connections between nodes, the students first attend to the website vaccin.me and in the next episode we will show how students struggle to understand the claims made on that website.

\section{Episode 4: Struggling to understand knowledge claims}

In the final episode analysed, the students examine the website vaccin.me with the hypothesis that it is incorrectly colored blue ("media") since it is so closely located to two other actors on the map that are clearly against the HPV vaccine (Mothers against Gardasil and Life after the vaccine.me They read claims on the website to decide whether they can be interpreted as being against the vaccine. Prior to the exchange below, Ted had assertively claimed that the website was against the vaccine based on a claim Ana read out loud, but instead of simply agreeing with him, Ana and Vicky continue to examine claims on the website. Ana directs their attention to another claim on a page with the heading: "Vaccine and side effects: propaganda for another round of vaccines is in full swing":

\section{Excerpt 4}




408 Vicky: yes

409 Ana: ( (looking at Ted)) that it

410 Vicky: yes they mean that

411 Ted: yes

412 Ana: But in that case it is against. "One should be skeptical of propaganda for this vaccine" ( (pointing her finger where she reads)) 413 Vicky: against?

414 Ana: or not against ( (showing “ "with hands), but it has a 415 Ted: (healthy?)

416 Vicky: HPV then all things we can find like public health authorities ( (looking at Ted) ) and 117

$417 \mathrm{Ted}$ : when was this written? ((looking at Ana's screen) )

418 Vicky: and Medical products agency

419 Ana: ( (scrolling up)) 2011

420 Vicky: and cancer association, and like all things and all kind of public pages and stuff is telling that HPV causes cervical cancer or can cause cervical cancer

421 ( (Ted is turning to his computer) )

422 Ana: yes

$423 \mathrm{Vicky}$ : so that thing feels a little made-up

$424 \mathrm{Ted}$ : color it a little pink then

425 Ana: yes ( (leaves the website and colors the node pink (Fig. 11)))

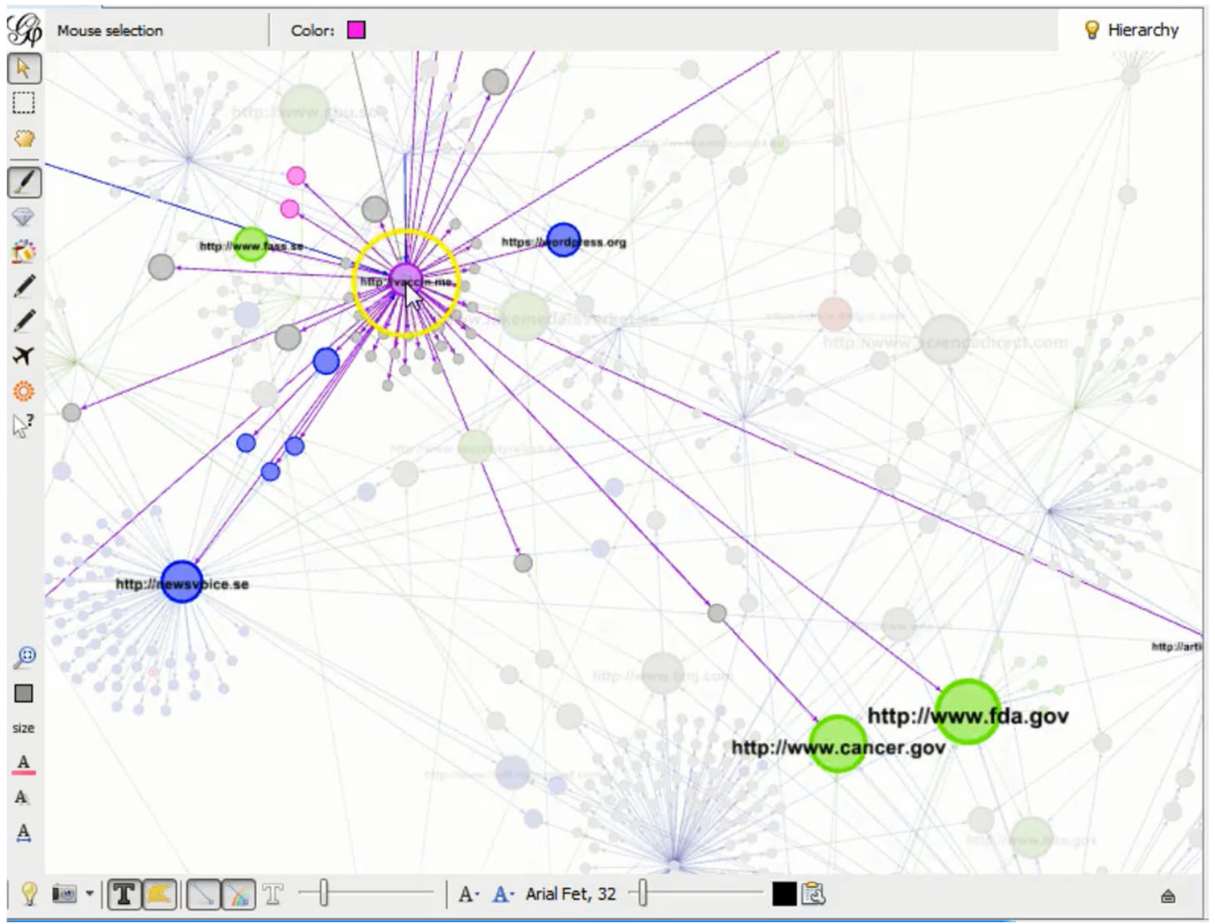

Fig. 11 Ana changes the color of node "vaccine.me" from blue (media) to pink ("against the vaccine") 
In this excerpt, the students are engaged in making sense of statements on vaccin.se. Throughout the activity, Ana and Ted focuses their attention on the websites in order to establish a category. They read and interpret claims to see whether they can understand them as taking a stance against the vaccine (400- 412). Vicky is also engaged in interpreting the claims, but focused on evaluating the trustworthiness of the claims. She is critical to claims questioning that papilloma viruses cause cervical cancer, but her statements seem to be ignored as Ana and Ted discuss the year the webpage was published (416-420). Their struggle to understand the claims in order to categorize the website ends when Ted responds to Vicky's critical evaluation "so that things feels a little made-up" with "color it a little pink then" (424).

In this episode, we see how the students in interaction change an earlier categorization made by the auto-coloring feature of the software (shown in Excerpt 1). Ted's utterance: "color it a little pink then" might be seen as a peculiar response to Vicky's questioning the truthfulness of the claims made on the webpage. However, to say that they should color the node a "little pink" displays an understanding that the actor is not obviously against the HPV vaccine. As Vicky's questioning of the claims made on the page are not seen as contributing to resolving the categorization problem, suggesting "a little pink" category can be seen as a way to acknowledge Vicky's challenging of the claims while allowing the group to complete the categorizing of the node and move on to the next. In order to achieve coordinated action Ted must display to his interlocutors the intelligibility of the events they are engaged in, including the kind of activities that are in progress and what they expect to happen next (Linell 1998).

The software is not developed to provide users with visual means to determine whether the claims on the websites are trustworthy or substantiated with evidence. The category is discussed and specifically here brought up by Vicky, when she provides counterclaims to what is claimed at the page that it is not clear whether papillomavirus causes cancer $(416,418,420)$. The approach "to separate legitimate from illegitimate knowledge claims" is made relevant by the task provided by the teachers. In the task, the aims and purposes of this project is coupled to the goals in the curriculum. The activity Ana and Ted are engaged in using the tools for exploratory purposes, in line with the STS scholars that developed these tools, to render the actors and their relations available for interpretation (Marres 2015).

\section{Discussion}

In this study we have reported on how digital mapping tools developed for exploring and visualizing controversial issues in the STS field work together with the local context to mediate collaborative handling of online information. The study aligns with the key concern within CSCL of helping people effectively engage in handling multiple perspectives and uncertainties of information in the internet age (Wise and Schwarz 2017). It expands on previous studies of the role representations in the learning process (Kolloffel et al. 2011) by focusing on students' communication and adds to existing research on how representations/visualizations in curricular interventions become productive resources in the learning process (Furberg et al. 2013). In this way, the study further 
extends the research base by detailing ways network visualization tools may provide means for working out what is relevant and useful in extensive corpora of online data. The detailed analysis of chronologically organized episodes from one group of students reveals how they used and responded to the various mediating features of the tools; and how particular affordances and constraints interplayed with other mediational means in the local context. The findings point to several important issues related to the a core concern of CSCL, the unique advantages of interactive tools when used by collaborators during the course of their meaning making (Stahl et al. 2006).

The first issue of particular importance that we wish to highlight addresses how the network mapping technology supported students in selecting, analyzing, and critically reviewing online material. Throughout the selected episodes, the students did not merely simplify, but attempted to display the nodes neatly, focusing attention by coloring certain nodes, clearing out elements deemed irrelevant to the controversy, and attending to making a map that could be used for presentation in ways similar to those seen when the tools are used in university settings (Boechat and Venturini 2016). In this sense, the study provides another account of knowledge production rather than re-production in a collaborative process with and through digital technology that follows in the established tradition of descriptive studies in CSCL (Stahl et al. 2006). Specifically, it reveals the collaborative activity of making meaning from a vast diversity of information presented online opening up for a process where students' produce new knowledge in the form of maps by demonstrating skills in selecting, analyzing and critical reviewing. Both Google and the mapping tool, Gephi, make use of algorithms to order and display information, representing particular logics built on specific assumptions about what kind of information should be made prominent and how one should identify its most relevant components. In the classroom examined here, there is an interplay between Google's PageRank algorithm, Gephi's algorithms, and the mediational means that gain salience in the local context. The interplay of these algorithmic logics with the logics of instructional context guide students in identifying what they need to know and in selecting what is most relevant from a corpus of data consisting of traces of their activities and websites visited. This is in stark contrast to more traditional educational situations where students typically rely on teachers, experts or scientific methods (Schwendimann and Linn 2016). In the case of Gephi, the developers have intended to guide the interpretation of data in particular ways by grouping nodes (websites in this study) that are connected by many edges (hyperlinks in this study), making the assumption that the more connected nodes are, the more they have in common (Jacomy et al. 2014). The layout algorithm used in this study, ForceAtlas, mediates the way that the corpus of websites is visually organized and thus how meaning may be made of its topography, but this process relies solely on the quantity of edges between nodes leaving the algorithm blind to the particular attributes of the nodes themselves. In this way, the tool operates on the corpus of websites with a distinctly different logic to the students who extensively attend to the content of the different websites in trying to make meaning of how a controversy is presented online.

Highlighting the issue of alignment between the tools and the students' logics, in Episodes1-3 we see how the students collaboratively interact with the tools and use them for the purposes of the project at hand. This is similar to many earlier CSCL studies (cf. Furberg 2016; Kolloffel et al. 2011), however, the case examined in this study follows in the tradition of a smaller group of CSCL projects that have investigated the collaborative use of non-school specific technologies in school settings (cf. Cekaite 2009; Forte 2015). The mapping tools studied here were developed for research in science and technology studies and are not always 
aligned with the school project where students are faced with the challenge to categorize the content of what appears in the map as nodes while the software is only operating on the relationship between nodes agnostic to their content relationships. It has been argued that it isn't necessarily the best possible alignment by tools to students' logic that produce the best pedagogical result and that in fact some mismatches between a tool's logic and the process students engage in might be beneficial (Hillman 2014). In this sense, the analysis in this paper reveals how aspects of the tools became what Davis and Sumara (2014) refer to as 'enabling constraints'. That is, structural conditions that help to create a balance between coherence and randomness, or in this case between a certain way of describing controversies and the freedom to freely explore. Our findings suggest that exposing students to tools developed for slightly different settings and processes was productive as it prompted students to engage in the exploration and negotiation of how to make sense of the controversy, as well as of the maps themselves. In particular, students are seen to be involved in elaborate and potentially productive discussions in episode 2 where they discuss the difference between the controversy per se and the visualization they have made to explain it.

A number of software applications have been developed to support learning about complex systems, such as social network graphs that provide visualization affordances that have been reported to have moved students to a more complex understanding of SSIs (Yoon 2011). One particular affordance with the mapping tool used here is that it slowed down the process of examining and categorizing the actors as students worked to represent the SSI complexity through emergent categories. The students summarized the controversy in terms of three emergent category schemes that described actors as institutions such as media and government agencies, as being positioned as opposing the vaccine, and as trustworthy or not. The students assembled elements that did not fit together into larger schemes. They handled a variety of orders: types of actors, discourses, and logics. Law and Mol (2002) have described how, when addressing complexities in the social sciences, different orders work and relate in different ways. Regarding the SSIs the students rendered legible here different nodes of ordering, different types of justification for inclusion and different discourses overlapped and interfered with one another. For instance, the students established a category "opposed to the vaccine", but no category "in favor of the vaccine", a category which might be expected to be established when mapping a controversy. But many of the sites categorized as governmental institutions could in fact be categorized as being in favor of vaccination, and are examples of how the different possible categories and ways to order the actors overlaps.

A final issue that we will address concerns how the tool challenges and is challenged by the science curriculum. An interesting contribution from the use of these digital mapping tools and an illustrative example of how the tools are challenging school, or the goals of the school subject science, is exemplified in Episode 4. The curriculum states that students are to separate scientific from non-scientific claims. We have demonstrated how the students struggled to understand claims made by actors that were opposed to the vaccine, and not simply dismiss them as "made up" by evaluating them in terms of trustworthiness. The mapping method allows for the presence of what can be termed 'disagreeing minorities'. Vicky worked according to what can be described as a demarcationist approach, which is alluded to in the curriculum as well, to use the mapping to adjudicate between sources. With such an approach, the idea is to identify trustworthy and reliable sources from others. Making credibility judgments and coming to a shared understanding of what constitutes credibility has become an important aspect of engaging with social media and the internet more generally in classrooms (Forte 2015). The STS scholars that developed the tools used in this study on 
the other hand, primarily aim to facilitate the exploration of controversy. They work according to the principle that cartographers would respect the actors they observe and thus not neglect actors' ideas just because they are not based on scientific theory or methodology (Venturini 2010b). Controversy analysis does not seek to establish the legitimacy of knowledge disputes, but instead uses tools for exploratory purposes; namely to detect relations between substantive arguments and socially and politically located actors and to render such relations available for interpretation. There is a tension between these two different approaches one can take to understanding controversies, with both sides seen in the classroom studied. One approach is made relevant by the curriculum and the traditional science education approach and the other by the STS approach to using the mapping tools.

\section{Implications for research and practice}

In the following concluding remarks, some implications for educational research and practice raised by this study will be discussed along with an account of the limitations of the current study. The research approach taken here contributes to fundamental understanding of how students collaboratively interact with tools introduced to explore and visualize SSIs encountered unfiltered on the Internet. In this study, to support collaborative learning and knowledge building, we contribute with a detailed report on how small groups of learners construct shared meaning using various artifacts and media in line with an established tradition of CSCL studies (Stahl et al. 2006). We have offered a sociocultural framework as a plausible approach for unpacking rich descriptions of student practices with an analysis aimed at revealing what students are doing in moment-to-moment interaction. For those who ask evaluative questions regarding the effectiveness of teaching and learning, this approach is clearly limiting. However, this work, including a previous study (Solli et al. 2017) where we described how students share the map with peers and use it to point out stakeholders, explain their arguments and discuss the reliability of various sites, contributes to providing an analytic grounding for informing the design of tools in better resonance with existing practices. This ground is also equally valuable for applied research that engages with normative considerations for developing classroom practices concerning the handling complex issues presented online.

In this study, we focus on the use of the mapping software by reporting on an attempt to introduce digital mapping tools developed for university courses in STS to science in upper secondary school. No doubt the students in this study do not make as rich maps as STS university students who are taught by scholars dedicated to this area. And the students not captured in the data and not chosen for analysis might have encountered more problems than the group we report on here. We chose to analyze the creation of a map that was rather complex and thoroughly worked on. The student group selected for analysis in this study managed the difficult task of making a complex network visualization more legible and communicable to other students. The students in the group used the digital mapping tool that offers multiple affordances in one tool. It enabled navigation through data from zooming in on a single data-point and out to a "landscape" of connected data points - accordingly moving from an overview, zooming and focusing on details if necessary and filter data for more relevant visualizations. The students in our example were encouraged to engage with their networks and sometimes to struggle with them, to challenge and search for justification for the previous decisions on categories and open up to findings that they may not have thought about. Similar to the findings that concept maps compared to expert knowledge provided means for 
students to work out what is relevant and useful (Schwendimann and Linn 2016), the work with the visual representation and supported by guiding questions oriented the students towards what was relevant and useful when exploring controversies rather than merely focusing on the somewhat simple dichotomy between scientific and unscientific claims that is attended to in the curriculum.

In our study, however, the students had to handle a very complex task when working with one map where they needed to determine: 1) who the actors were 2) what their arguments were 3 ) how they were connected to other actors in the controversy 4) when things were written etc. In this project within a period of three weeks, we decided to work with this combination of webcrawling and network visualization tools for students to make one map. For future work we would in accordance with Venturini et al. (2015) suggest that students make if not a collection of maps, an atlas, at least some with different views of the controversy such as levels of detail, ways of categorizing actors, and techniques of representation. In addition to showing the network of actors as students did in this study one map could visualize what is debated in the controversy and how knowledge claims are connected to other claims or topics. In this way, students would show that statements in controversies are not isolated, but always connected in dialogues. A second map would map out who is involved in the controversy. Plotting who shares arguments in a so called "actors- arguments table" is often suggested when mapping controversies. In addition to presenting what controversies are about, who is involved in them and how they join or oppose their forces, students could also show how a controversy evolves in time. We would agree with Venturini el al. that it seems important to "break down the richness of a controversy and then rebuild it through a chain of subsequent representations" (Venturini et al. 2015, p 80). Attempting to make one single map in order to keep together the complexity of controversies and make it legible is a particularly difficult task, but many maps gathered in 'an atlas' might be more manageable.

Developing controversy mapping into a commonplace tool in schools would require significant development work on the tools and require support for teachers faced with the challenge of choosing when, whether and how to use them. This study offers an initial exploration of the possibilities for supporting educational activities with these tools, but continued examination of the different ways teachers might take up these digital mapping tools would be an important area for further investigation. In order for these tools to work in upper secondary education settings where teachers are not focused on digital methods or controversy mapping per se (as is the situation in the university courses where these tools have been used previously), a key question is how controversy mapping tools and approaches can be designed when the aims are not focused on research and advanced courses in higher education, but instead on usefulness, reliability, and sustainability for educational settings. Further development is needed before these methods and software are made widely available to upper secondary schools in general. Although a new a webcrawling tool, Hyphe, is currently under development, work needs to be done to develop software and accompanying pedagogical approaches that are stable, supported and tailored so that teachers not specifically trained to handle these programs can use them successfully given the limited time available in schools for teachers to engage in exploring new tools and approaches.

As mentioned at the beginning of this paper, providing students with opportunities for handling complex information online is necessary for developing democratic literacy. Two decades ago, the Internet was frequently viewed through a utopian lens; scholars espoused that online search results would provide citizens with viewpoint diversity. More recently we have become aware of how search engines and algorithms distribute, shape, suppress or bias 
information and it is pertinent that schools play a role in giving students the opportunity to examine and reflect upon this situation. With increased opportunities to choose internet based resources for educational purposes and the accompanying challenge to support students to develop the skills required for digital participation, we are only beginning to understand how students could be learning and participating as citizens in the digital age (Wise and Schwarz 2017). In this paper, we illustrate the importance of mediational means provided by the features of a digital mapping tool and how learning about the technical side of the visual representation, was integral to this process. The results of our study suggest that instructional approaches committed to dialogical interaction, and which incorporate the use of digital visualization tools producing controversy maps, show promise for analyzing online material and handling the complexity of SSI discourses introduced in the classroom.

Acknowledgements The research reported is funded by the Swedish Research Council. It has been conducted within the University of Gothenburg LETStudio group and as part of the LinCS research environment, a 10 year funded $\mathrm{CoE}$ for research on learning, interaction and IT. We would especially like to thank the anonymous reviewers and our colleagues in both the LETStudio group and in the Sociocultural and Dialogical Studies seminar who provided comments on an earlier draft of this text.

\section{Appendix 1: Transcript conventions}

[text] Simultaneous/overlapping utterances

(3 s) Shows pauses from $1 \mathrm{~s}$ and longer

(.) Pauses shorter than one second

? Marks intonation of a question

Falling pitch or intonation

Text Underlining indicates emphasis

$(($ text $))$ Transcribers' commentaries on: inaudibility, nonverbal aspects, characterizations of how talk was delivered, extra discursive activities

text $^{\circ} \quad$ Indicates reduced volume speech

$<$ text $>$ Indicates that enclosed speech was delivered more rapidly than usual for the speaker "text" When speaker read text on screen out loud

Open Access This article is distributed under the terms of the Creative Commons Attribution 4.0 International License (http://creativecommons.org/licenses/by/4.0/), which permits unrestricted use, distribution, and reproduction in any medium, provided you give appropriate credit to the original author(s) and the source, provide a link to the Creative Commons license, and indicate if changes were made.

Publisher's Note Springer Nature remains neutral with regard to jurisdictional claims in published maps and institutional affiliations.

\section{References}

Arnseth, H. C., \& Ludvigsen, S. (2006). Approaching institutional contexts: Systemic versus dialogic research in CSCL. International Journal of Computer-Supported Collaborative Learning, 1(2), 167-185

Boechat, M., \& Venturini, T. (2016). From analysis to presentation. Les Cahiers Du Numérique, 12(4), $185-196$.

Cekaite, A. (2009). Collaborative corrections with spelling control: Digital resources and peer assistance. International Journal of Computer-Supported Collaborative Learning, 4(3), 319-341. https://doi. org/10.1007/s11412-009-9067-7. 
Choi, M., Glassman, M., \& Cristol, D. (2017). What it means to be a citizen in the internet age: Development of a reliable and valid digital citizenship scale. Computers \& Education, 107(Supplement C), 100-112. https://doi.org/10.1016/j.compedu.2017.01.002.

Chung, J. S., \& Neuman, D. (2007). High school students' information seeking and use for class projects. Journal of the American Society for Information Science and Technology, 58(10), 1503-1517. https://doi. org/10.1002/asi.20637.

Davis, B., \& Sumara, D. (2014). Complexity and education: Inquiries into learning, teaching, and research. Taylor \& Francis. Retrieved from https://books.google.se/books?id=nHW3AwAAQBAJ.

Eggert, S., Nitsch, A., Boone, W. J., Nückles, M., \& Bögeholz, S. (2017). Supporting students' learning and Socioscientific reasoning about climate change-The effect of computer-based concept mapping scaffolds. Research in Science Education, 47(1), 137-159. https://doi.org/10.1007/s11165-015-9493-7.

Flaxman, S., Goel, S., \& Rao, J. (2016). Filter bubbles, Echo chambers, and online news consumption. Public Opinion Quarterly, 80, 298.

Forte, A. (2015). The new information literate: Open collaboration and information production in schools. International Journal of Computer-Supported Collaborative Learning, 10(1), 35-51. https://doi.org/10.1007 /s11412-015-9210-6.

Furberg, A. (2016). Teacher support in computer-supported lab work: Bridging the gap between lab experiments and students' conceptual understanding. International Journal of Computer-Supported Collaborative Learning, 11(1), 89-113. https://doi.org/10.1007/s11412-016-9229-3.

Furberg, A., Kluge, A., \& Ludvigsen, S. (2013). Student sensemaking with science diagrams in a computerbased setting. International Journal of Computer-Supported Collaborative Learning, 8(1), 41-64. https://doi.org/10.1007/s11412-013-9165-4.

Granka, L. A. (2010). The politics of search: A decade retrospective. The Information Society, 26(5), 364-374.

Hillman, T. (2014). Tracing the construction of mathematical activity with an advanced graphing calculator to understand the roles of technology developers, teachers and students. The International Journal for Technology in Mathematics Education, 21(2), 37-47.

Hmelo-Silver, C. E., Marathe, S., \& Liu, L. (2007). Fish swim, rocks sit, and lungs breathe: Expert-novice understanding of complex systems. Journal of the Learning Sciences, 16(3), 307-331. https://doi. org/10.1080/10508400701413401.

Hsu, C.-Y., Tsai, M.-J., Hou, H.-T., \& Tsai, C.-C. (2014). Epistemic beliefs, online search strategies, and behavioral patterns while exploring Socioscientific issues. Journal of Science Education and Technology, 23(3), 471-480. https://doi.org/10.1007/s10956-013-9477-1.

Introna, L. D., \& Nissenbaum, H. (2000). Shaping the web: Why the politics of search engines matters. The Information Society, 16(3), 169-185. https://doi.org/10.1080/01972240050133634.

Jacomy, M., Venturini, T., Heymann, S., \& Bastian, M. (2014). ForceAtlas2, a continuous graph layout algorithm for handy network visualization designed for the Gephi software. PLoS One, 9(6), e98679.

Jordan, B., \& Henderson, A. (1995). Interaction analysis: Foundations and practice. The Journal of the Learning Sciences, 4(1), 39-103.

Klosterman, M. L., Sadler, T. D., \& Brown, J. (2012). Science teachers' use of mass media to address socio-scientific and sustainability issues. Research in Science Education, 42(1), 51-74. https://doi.org/10.1007/s11165-0119256-z.

Knight, S., \& Mercer, N. (2014). The role of exploratory talk in classroom search engine tasks. Technology, Pedagogy and Education, 1-17. https://doi.org/10.1080/1475939X.2014.931884.

Kolloffel, B., Eysink, T., \& de Jong, T. (2011). Comparing the effects of representational tools in collaborative and individual inquiry learning. International Journal of Computer-Supported Collaborative Learning, 6(2), 223-251. https://doi.org/10.1007/s11412-011-9110-3.

Krange, I., \& Arnseth, H. C. (2012). Students' meaning making in science: Solving energy resource problems in virtual worlds combined with spreadsheets to develop graphs. Cultural Studies of Science Education, 7(3), 585-605. https://doi.org/10.1007/s11422-011-9361-3.

Law, J., \& Mol, A. (Eds.). (2002). Complexities. Social studies of knowledge practices. Durham: Duke University Press.

Lin, C.-C., \& Tsai, C.-C. (2012). Participatory learning through behavioral and cognitive engagements in an online collective information searching activity. An Official Publication of the International Society of the Learning Sciences, 7(4), 543-566. https://doi.org/10.1007/s11412-012-9160-1.

Linell, P. (1998). Approaching dialogue: Talk, interaction and contexts in dialogical perspectives. Amsterdam: Johns Benjamins.

Marres, N. (2015). Why map issues? On controversy analysis as a digital method. Science Technology \& Human Values, 40(5), 655-686.

Pedretti, E., \& Nazir, J. (2011). Currents in STSE education: Mapping a complex field, 40 years on. Science Education, 95, 601-626. 
Säljö, R. (1999). Learning as the use of tools. London: Routledge.

Säljö, R. (2010). Digital tools and challenges to institutional traditions of learning: Technologies, social memory and the performative nature of learning: The performative nature of learning. Journal of Computer Assisted Learning, 26(1), 53-64. https://doi.org/10.1111/j.1365-2729.2009.00341.x.

Schwendimann, B. A., \& Linn, M. C. (2016). Comparing two forms of concept map critique activities to facilitate knowledge integration processes in evolution education. Journal of Research in Science Teaching, 53(1), 70-94. https://doi.org/10.1002/tea.21244.

Selwyn, N. (2011). Schools and schooling in the digital age: A critical analysis. London: Routledge.

Solli, A., Hillman, T., \& Mäkitalo, Å. (2017). Navigating the complexity of socio-scientific controversiesHow students make multiple voices present in discourse. Research in Science Education. https://doi. org/10.1007/s11165-017-9668-5.

Stadtler, M., \& Bromme, R. (2007). Dealing with multiple documents on the WWW: The role of metacognition in the formation of documents models. Computer-Supported Collaborative Learning, 2(2), 191-210. https://doi.org/10.1007/s11412-007-9015-3.

Stahl, G., Koschmann, T. D., \& Suthers, D. D. (2006). Computer-supported collaborative learning. na.

Venturini, T. (2010a). Building on faults: How to represent controversies with digital methods. Public Understanding of Science, 21(7), 796-812.

Venturini, T. (2010b). How to represent controversies with digital methods. Public Understanding of Science, 21(7), 796-812.

Venturini, T., \& Latour, B. (2010). The social fabric: Digital traces and qual-quantatitive methods. Retrieved from (www.medialab.sciences-po.fr/publications/Venturini LatourThe Social Fabric.pdf).

Venturini, T., Ricci, D., Mauri, M., Kimbell, L., \& Meunier, A. (2015). Designing controversies and their publics. Design Issues, 31(3), 74-87. https://doi.org/10.1162/DESI_a_00340.

Walsh, E., \& Tsurusaki, B. (2017). "Thank you for being republican": Negotiating science and political identities in climate change learning. Journal of the Learning Sciences. https://doi.org/10.1080/10508406.2017.1362563.

Wertsch, J. V. (1998). Mind as action. New York: Oxford University Press.

Wise, A. F., \& Schwarz, B. B. (2017). Visions of CSCL: Eight provocations for the future of the field. International Journal of Computer-Supported Collaborative Learning, 12(4), 423-467. https://doi. org/10.1007/s11412-017-9267-5.

Wu, Y.-T., \& Tsai, C.-C. (2011). The effects of different on-line searching activities on high school students' cognitive structures and informal reasoning regarding a socio-scientific issue. Research in Science Education, 41(5), 771-785. https://doi.org/10.1007/s11165-010-9189-y.

Yoon, S. A. (2011). Using social network graphs as visualization tools to influence peer selection decisionmaking strategies to access information about complex Socioscientific issues. Journal of the Learning Sciences, 20(4), 549-588. https://doi.org/10.1080/10508406.2011.563655.

Zeidler, D. L. (2014). Socioscientific issues as a curriculum emphasis. Theory, research and practice. In S. Abell \& N. Lederman (Eds.), Handbook on research in science education (Vol. 1-II, pp. 697-726). New York: Routledge. 